\title{
Analisis Rencana Tarif Jalan Tol Berdasarkan Pendekatan Ability To Pay (ATP) Dan Willingness To Pay (WTP) Pada Rencana Ruas Jalan Tol Sigli - Banda Aceh
}

\author{
Faisal $^{1}$, M. Isya ${ }^{2}$, Fitrika Mita Suryani ${ }^{3}$ \\ 1) Mahasiswa Teknik Sipil Universitas Syiah Kuala 2311 Banda Aceh \\ 2,3) Dosen, Jurusan Teknik Sipil Universitas Syiah Kuala, Banda Aceh 23111, Indonesia \\ email: faisalsyahrul111@gmail.com
}

\begin{abstract}
The construction of toll roads is one of the government's efforts in facilitating the community to be able to carry out their mobility both in economic and social terms well and quickly. The construction of toll roads is also expected to be able to pass traffic with a safer, more comfortable and smoother level of service. Therefore, the government and related parties plan to build toll road in Aceh. It has 4 (four) roads with a total length of $455 \mathrm{~km}$ consisting of the $110 \mathrm{~km}$ of Binjai Langsa toll road, $135 \mathrm{~km}$ of Langsa - Lhokseumawe toll road, $135 \mathrm{~km}$ of Lhokseumawe - Sigli toll road, and $75 \mathrm{~km}$ of Sigli - Banda Aceh toll road. The construction of the first toll road in Aceh will be started on the Sigli - Banda Aceh road corridor, and the construction or placement of the first stone will be started from Banda Aceh. The toll road construction has become the first toll road in Aceh. Consequently, the government has not yet set an official tariff. The purpose of this study is to determine and obtain effective rates based on analysis of the Ability to Pay (ATP) and Willingness to Pay (WTP) toll road tariffs. This research consists of data collection, namely primary and secondary data. Primary data are obtained based on direct observations in the field whereas for secondary data obtained from the relevant agencies. The data that has been obtained is then continued to the tariff analysis stage by using the ATP and WTP formulas. From the results of this analysis it can be concluded that the recommended tariff for the Sigli - Banda Aceh Toll Road is based on the average value of Ability To Pay (ATP) and Willingness To Pay (WTP) for class I (LV) vehicles of Rp. 56,000, - for class IIA (MHV) vehicles in the amount of Rp. 152,000, -for class IIB (LT \& LB) vehicles amounting to Rp. 118,500.
\end{abstract}

Keywords: Toll Road, ATP, WTP, Toll Rates.

\begin{abstract}
Abstrak
Pembangunan jalan tol merupakan salah satu usaha pemerintah dalam memudahkan masyarakat untuk bisa melakukan mobilitas mereka baik dalam hal ekonomi maupun sosial dengan baik dan cepat. Pembangunan jalan tol juga diharapkan dapat melewatkan trafik dengan tingkat pelayanan yang lebih aman, nyaman, dan lancar. Pemerintah dan pihak terkait berencana untuk membangun ruas jalan tol Aceh, untuk ruas jalan tol itu sendiri memiliki 4 (empat) ruas jalan dengan panjang total $455 \mathrm{~km}$ yang terdiri dari ruas jalan tol Binjai - Langsa $110 \mathrm{~km}$, ruas jalan tol Langsa Lhokseumawe $135 \mathrm{~km}$, ruas jalan tol Lhokseumawe - Sigli $135 \mathrm{~km}$, ruas jalan tol Sigli - Banda Aceh $75 \mathrm{~km}$. Sedangkan untuk pembangunan jalan tol pertama di Aceh ini dimulai pada koridor ruas jalan Sigli - Banda Aceh, dan untuk pengerjaan atau perletakan batu pertamanya dimulai dari Banda Aceh. Pembangunan jalan tol tersebut menjadi jalan tol pertama di Aceh, dan Pemerintah belum menetapkan tarif yang resmi. Tujuan penelitian ini untuk mengetahui dan mendapatkan tarif efektif berdasarkan analisis Ability To Pay (ATP) dan Willingness To Pay (WTP) tarif jalan tol. Penelitian ini terdiri dari pengumpulan data yaitu data primer dan data sekunder. Data primer diperoleh berdasarkan pengamatan langsung di lapangan. Sedangkan untuk data sekunder diperoleh dari instansi terkait. Data yang telah diperoleh kemudian dilanjutkan ke tahap analisis tarif dengan cara menggunakan rumus ATP dan WTP. Dari hasil analisis tersebut dapat disimpulkan bahwa tarif yang direkomendasikan untuk Jalan Tol Sigli - Banda Aceh berdasarkan nilai ratarata Ability To Pay (ATP) dan Willingness To Pay (WTP) untuk kendaraan golongan I (LV) sebesar Rp 56.000,-, untuk kendaraan golongan IIA (MHV) sebesar Rp 152.000,-, untuk kendaraan golongan IIB (LT \& LB) sebesar Rp 118.500,-.

Kata kunci : Jalan Tol, ATP, WTP, Tarif Tol.
\end{abstract}

\section{Pendahuluan}

Pembangunan jalan tol merupakan salah satu usaha pemerintah dalam memudahkan masyarakat untuk bisa melakukan mobilitas mereka baik dalam hal ekonomi maupun sosial dengan baik dan cepat. Jalan tol merupakan proyek yang diharapkan pemerintah dapat mengurai kemacetan sampai dapat menjadi sumber pemasukan kas Negara. Salah satu Mega Proyek Jalan Tol yang saat ini sedang dikerjakan adalah Proyek Jalan Tol Trans Sumatera.

Keberadaan jalan nasional yang menghubungkan Kota Sigli dan Kota Banda Aceh mengalami penurunan pelayanan yang diberikan jalan tersebut (level of service) terhadap pengguna jalan. Penurunan pelayanan berupa waktu tempuh yang lama dan dinilai kurang efisien, dimana perjalanan yang harus ditempuh biasanya sekitar $110 \mathrm{~km}$ dalam kurun waktu 2,5 jam. Berdasarkan hal tersebut maka untuk mengatasi permasalahan ini akan dilakukan pembangunan jalan tol untuk melewatkan traffic dengan tingkat pelayanan yang lebih aman, nyaman, lancar bahkan ekonomis.

Pemerintah dan pihak terkait berencana untuk membangun Jalan Tol Sigli-Banda Aceh. Jalan tol ini diharapkan dapat mempelancar laju arus lalu lintas dari Sigli menuju Banda Aceh ataupun sebaliknya serta bebas hambatan, yang artinya jalan tol memiliki fungsi khusus 
dalam mempelancar lalu lintas. Jalan tol Aceh ini sendiri memiliki 4 (empat) ruas jalan dengan panjang total $455 \mathrm{~km}$ yang terdiri dari ruas jalan tol Binjai - Langsa $110 \mathrm{~km}$, ruas jalan tol Langsa - Lhokseumawe $135 \mathrm{~km}$, ruas jalan tol Lhokseumawe - Sigli $135 \mathrm{~km}$, ruas jalan tol Sigli - Banda Aceh $75 \mathrm{~km}$.

Penelitian ini dilakukan dikarenakan jalan tol tersebut belum beroperasi dan belum memiliki tarif tol, maka penelitian ini ditujukan untuk menentukan tarif tol yang nantinya dapat digunakan sebagai bahan informasi kepada pemangku kepentingan dalam menetapkan tarif jalan tol saat dioperasikan nanti. transportasi.

\subsection{Rumusan Masalah}

Berdasarkan latar belakang yang telah diuraikan di atas maka dapat diidentifikasi masalah sebagai berikut : 1. Berapa besarnya nilai Willingness To Pay (WTP) untuk membayar jalan tol?

2. Berapa besarnya nilai Ability To Pay (ATP) untuk membayar jalan tol?

\subsection{Tujuan Penelitian} berikut:

Adapun tujuan penulisan ini adalah sebagai

1. Untuk mengetahui berapa besar keinginan atau kemauan dalam membayar biaya tol?

2. Untuk mengetahui berapa besar kemampuan dalam membayar biaya tol?

\subsection{Manfaat Penelitian}

Manfaat yang dapat diberikan dari penelitian ini adalah sebagai berikut:

1. Untuk bahan pertimbangan pemerintah atau pihak terkait dalam menentukan atau memutuskan kebijakan tarif tol Sigli - Banda Aceh.

2. Untuk bahan informasi bagi mahasiswa teknik sipil pada khususnya dan masyarakat pada umumnya, mengenai kemampuan atau daya bayar masyarakat terhadap jalan tol Sigli - Banda Aceh.

\subsection{Batasan Masalah} sebagai berikut:

Adapun batasan masalah dari penelitian ini adalah

1. Penelitian ini mengambil responden dengan meneliti potensi orang-orang yang sering melintasi jalan Banda Aceh - Sigli sebagai jalan nasional untuk jalan tol Sigli - Banda Aceh nantinya.

2. Analisa tarif yang dilakukan dalam penelitian ini adalah pada kendaraan golongan I (LV), golongan IIA (MHV), dan golongan IIB (LT \& LB).

3. Penelitian ini hanya meninjau atau melihat kemampuan membayar dan keinginan membayar besarnya biaya tarif rencana ruas jalan tol Sigli - Banda Aceh dari sisi pengguna jalan tol tersebut nantinya.

4. Dalam penelitian ini penulis hanya fokus dalam menghitung ATP dan WTP saja, sedangkan untuk Analisis Investasi Finansial/keuangan dan nilai ekonomi tidak dianalisis dalam penelitian ini.
Menurut Undang-undang Negara Republik Indonesia No. 38 Tahun 2004 tentang Jalan, Jalan Tol adalah jalan umum yang merupakan bagian sistem jaringan jalan dan sebagai jalan nasional yang penggunanya diwajibkan membayar tol. Jalan tol sendiri diselenggarakan untuk :

a.Mempelancar lalu lintas di daerah yang telah berkembang;

b.Meningkatkan hasil guna dan daya guna pelayanan distribusi barang dan jasa guna menunjang peningkatan pertumbuhan ekonomi;

c.Meringankan beban dana pemerintah melalui partisipasi pengguna jalan; dan keadilan.

d.Meningkatkan pemerataan hasil pembangunan

Pengusahaan jalan tol dilakukan oleh pemerintah atau badan usaha yang telah memenuhi persyaratan. Jalan tol memiliki tarif tol tertentu yang harus dibayarkan oleh pengguna jasa jalan tol tersebut yang nantinya tarif tersebut akan digunakan untuk pengembalian investasi, pemeliharaan, dan pengembangan jalan tol.

\subsection{Tarif Tol}

Menurut Warpani (2002), tarif adalah harga jasa angkutan yang harus dibayar oleh pengguna jasa, baik melalui mekanisme perjanjian sewa menyewa, tawar menawar, maupun ketetapan Pemerintah. Harga jasa angkutan yang ditentukan mengikuti tarif, berlaku secara umum dan tidak ada ketentuan lain yang mengikat perusahaan angkutan dan pemilik barang atau penumpang kecuali apa yang sudah diatur dalam buku tarif. Menurut Tamin (2008), ada beberapa macam prinsip umum yang melandasi penentuan tarif, yaitu yang didasarkan pada:
a) Jumlah penumpang dan karakteristik penumpang.
b) Karakteristik penumpang angkutan umum.
c) Biaya operasional kendaraan.

\subsection{Jenis Tarif Tol}

Menurut Saiful (2006), jenis tarif yang berlaku dapat dikelompokkan sebagai berikut:
a. Tarif Seragam (flate fare)
b. Tarif Kilometer
c. Tarif Bertahap

\subsection{Ability To Pay}

Menurut Tamin (2008), ATP merupakan kemampuan seseorang untuk membayar jasa pelayanan yang diterima berdasarkan penghasilan yang dianggap ideal. Pendekatan yang digunakan dalam analisa ATP didasarkan pada alokasi biaya untuk transportasi dari pendapatan rutin yang diterimanya. Dengan kata lain, ATP adalah kemampuan masyarakat dalam membayar ongkos (tarif) perjalanan yang dilakukannya.

\subsection{Willingness To Pay}

Menurut Menurut Tamin (2008), WTP adalah kemauan pengguna jasa memberikan suatu bayaran atas 
jasa yang diperoleh. Pendekatan yang digunakan adalah berdasarkan persepsi terhadap tarif dari jasa transportasi tersebut. Sasaran dari WTP adalah mendapatkan besaran tarif tol yang paling optimum dan realistis sesuai keinginan atau kemauan membayar masyarakat namun masih tetap menarik investor untuk berinvestasi.

\subsection{Hubungan antara ATP dan WTP}

Menurut Tamin (2008), dalam penentuan tarif angkutan sering terjadi ketidaksesuaian antara ATP dan WTP. Ada beberapa kondisi yang mungkin terjadi, yaitu: a. ATP $>$ WTP

Kondisi ini menunjukkan kemampuan membayar lebih besar dari keinginan membayar jasa transportasi. Hal ini terjadi bila pengguna mempunyai penghasilan relatif tinggi tetapi utilitas terhadap jasa tersebut relatif rendah, pengguna pada kondisi ini disebut pengguna yang bebas memilih (choice riders).

b. $\quad \mathrm{ATP}=\mathrm{WTP}$

Menunjukan tingkat kemampuan dan keinginan pengguna dalam membayar jasa yang dikonsumsi itu sama besar. Pada kondisi ini telah terjadi keseimbangan antara utilitas pengguna dengan biaya yang dikeluarkan oleh pengguna jasa tersebut.

c. ATP $<$ WTP

Kondisi ini menggambarkan keinginan pengguna untuk membayar jasa lebih besar dari kemampuan yang dimiliki. Hal ini mungkin terjadi bagi pengguna yang mempunyai penghasilan relatif rendah tetapi utilitas terhadap jasa tersebut sangat tinggi. Sehingga keinginan pengguna untuk membayar jasa tersebut relatif lebih dipengaruhi oleh utilitas, pada kondisi ini disebut captive riders.

\section{Metode Penelitian}

Pada bab ini akan dijelaskan secara lebih jelas metode yang digunakan dalam rencana penelitian, sumber data, cara pengambilan atau pengumpulan data, alat atau media yang digunakan, proses pengolahan data dan analisis lainnya untuk mendapatkan hasil penelitian. Secara garis besar, langkah kerja atau proses penyusunan dalam tugas akhir ini nantinya meliputi identifikasi masalah, persiapan awal dan studi terdahulu, pengumpulan dan pengolahan data, dan analisa tarif tol.

Langkah-langkah kerja untuk mengetahui arah penelitian dan parameter apa yang akan digunakan dapat dijelaskan secara sistematik di dalam bagan alir metode penelitian seperti yang terlihat pada Lampiran A.3.1. Dan untuk Peta provinsi Aceh dapat dilihat pada Lampiran A.3.2.

\subsection{Lokasi Penelitian}

Lokasi penelitian ini akan dilakukan pada ruas jalan tol Sigli - Banda Aceh dengan panjang untuk ruas tol itu sendiri $75 \mathrm{~km}$. Lokasi penelitian dapat dilihat pada Peta proyek pembangunan jalan tol Sigli - Banda Aceh yang terdapat pada Lampiran A.3.3 dan tipical potongan melintang jalan utama pada pembangunan jalan tol Sigli Banda Aceh pada Lampiran A.3.4.

\section{2}

\section{Lokasi Responden}

Survei yang dilakukan dalam penelitian ini dengan cara mewawancarai responden atau masyarakat yang ada di sekitaran daerah pembangunan jalan tol sebelum membagikan kuesioner, seperti di Terminal Angkutan Barang Santan, Terminal Bus Kota Banda Aceh, Terminal L300 Kota Banda Aceh, dan Rumah Makan Seulawah Indah Saree.

\subsection{Sketsa Rute Tol}

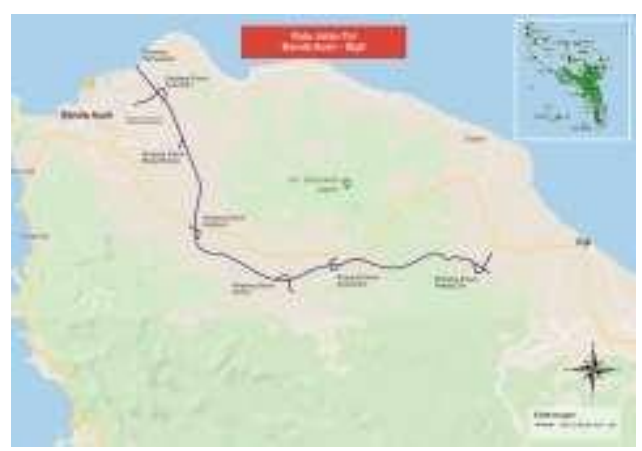

Sumber: Satuan Kerja dan Pengawasan Jalan Nasional Prov. Aceh BPJN I Banda Aceh

Dari sketsa rute tol di atas terdapat 6 (enam) rute tol sebagai berikut:

1. Padang Tiji - Seulimum;

2. Seulimum - Jantho;

3. Jantho - Indrapuri;

4. Indrapuri - Blang Bintang;

5. Blang Bintang - Kuta Baro, dan

6. Kuta Baro - Baitussalam.

\subsection{Menentukan Karakteristik Responden}

Pada penelitian ini kuesioner yang berisikan pertanyaan-pertanyaan mengenai data karakteristik responden, seperti nama responden, alamat, usia, jenis kelamin, nomor hp, pendidikan terakhir, jenis pekerjaan, aktivitas sehari-hari dalam penggunaan kendaraan, pengeluaran uang pribadi untuk transportasi sehari-hari.

Dalam penelitian ini salah satu data yang dibutuhkan adalah penghasilan rata-rata dan dan biaya pengeluaran untuk transportasi perbulan dalam suatu keluarga maka responden yang dibutuhkan dalam penelitian ini adalah kepala keluarga atau seorang tulang punggung dalam suatu keluarga tersebut. Untuk contoh pertanyaan dalam bentuk kuesioner yang akan dibagikan kepada masyarakat atau responden nanti akan dilampirkan pada Lampiran A.3.5 dan untuk foto penelitian akan dilampirkan pada Lampiran A.3.6.

\subsection{Populasi dan Jumlah Sampel}

Pada penelitian ini pengambilan sampel untuk data kuesioner ini diambil dari populasi masyarakat yang berusia 20-59 tahun yang ada di Kota Banda Aceh, Kabupaten Aceh Besar dan masyarakat Kabupaten Pidie. Seperti yang telah dijelaskan pada bab sebelumnya, penelitian ini pengambilan sampel menggunakan skala 
besar berkisar 100-200 sampel, dimana sampel yang diambil berjumlah 200 sampel.

\subsection{Teknik Pengumpulan Data}

Data yang dikumpulkan dalam penelitian berupa data primer dan data sekunder. Data primer adalah data yang didapatkan secara langsung dengan melakukan survei di lokasi penelitian, sedangkan data sekunder adalah sebagai data pendukung untuk penelitian ini, data tersebut dapat diperoleh melalui instansi terkait.

\subsection{Data Primer}

Data primer merupakan data yang didapatkan dengan cara melakukan kegiatan survei di lapangan langsung menggunakan kondisi yang ada. Adapun data primer yang diperlukan dalam penelitian ini sebagai berikut:

\section{a. Responden}

Responden pada penelitian ini berdasarkan jumlah populasi masyarakat yang berusia 20-59 tahun yang ada di Kota Banda Aceh, Kabupaten Aceh Besar dan masyarakat Kabupaten Pidie. Seperti yang telah dijelaskan pada bab sebelumnya, penelitian ini pengambilan sampel menggunakan skala besar berkisar 100-200 sampel, dimana sampel yang diambil berjumlah 200 sampel.

b. Hasil Wawancara Responden

Survei yang dilakukan dalam penelitian ini dengan cara mewawancarai responden atau masyarakat yang ada di sekitaran daerah pembangunan jalan tol sebelum membagikan kuesioner.

\subsection{Data Sekunder}

Data sekunder diperoleh dari dinas-dinas dan pihak terkait dalam pembangunan jalan tol tersebut baik secara langsung maupun tidak langsung menjadi bagian yang sangat penting yang akan sangat membantu dalam penelitian ini. Data sekunder meliputi:

a. Jarak/Panjang jalan tol

b. Data geografis

\section{9}

\section{Teknik Analisis}

Teknik Analisis tarif WTP dilakukan dengan cara menganalisa keinginan seseorang dalam membayar tarif tol yang harus dibayarkan nantinya berdasarkan pendapat mereka dan akan menjadi referensi atau pertimbangan bagi pemerintah maupun pihak pengelola tol nantinya. Begitu juga dengan Analisa tarif berdasarkan ATP adalah dengan menganalisa untuk mengetahui berapa kemampuan seseorang dalam membayar tarif tol berdasarkan pendapat mereka supaya ketentuan tarif tol tidak diputuskan oleh pihak pengelolanya saja tapi juga mempertimbangkan pendapat atau saran dari masyarakat tersebut.

\subsection{Data ATP}

ATP dipengaruhi oleh pendapatan, frekuensi perjalanan, dan perkiraan biaya transportasi setiap harinya, sehingga faktor-faktor yang digunakan untuk menentukan ATP terhadap jasa jalan tol adalah total pendapatan responden, alokasi pendapatan terhadap transportasi, dan alokasi biaya transportasi. Perhitungan nilai ATP menggunakan Persamaan (2.1).

\subsection{Data WTP}

Pendekatan yang digunakan dalam analisis WTP didasarkan atas tarif yang diharapkan. Variabel-variabel yang digunakan untuk menentukan WTP terhadap jasa jalan tol rencana ruas Sigli - Banda Aceh adalah tarif yang diharapkan, prioritas pelayanan yang diharapkan, dan kemauan membayar lebih untuk peningkatan keselamatan calon pengguna nantinya. Perhitungan nilai WTP menggunakan Persamaan (2.2) dan Persamaan (2.3).

\section{Hasil dan Pembahasan}

Bab ini akan mengemukakan hasil pengolahan dan analisis data yang didasarkan pada data yang diperoleh dari instansi yang terkait dan penyebaran kuesioner sesuai dengan metode penelitian dan pembahasan mengenai hasil penelitian yang dicapai dengan teori dan rumus-rumus yang telah dikemukakan pada tinjauan kepustakaan. Adapun hasil-hasil penelitian yang diperoleh akan diuraikan berikut ini.

\subsection{Hasil Penelitian}

Berikut ini diuraikan hasil-hasil penelitian yang diperoleh setelah pengumpulan data, pengolahan data dan analisis data.

\subsection{Karakteristik Responden}

Data yang diperoleh dari kuesioner dengan metode stated preference kemudian diolah untuk mendapat gambaran karakteristik responden yang telah berpartisipasi dalam pengisian kuesioner. Untuk hasil dari deskripsi statistik responden akan ditampilkan dalam bentuk diagram.

\section{a. Responden Berdasarkan Usia}

Responden adalah usia produktif dengan persentase paling tinggi berusia 25-29 tahun sebesar 18\%, kemudian responden yang berusia 20-24 tahun sebesar $16 \%$, responden yang berusia 30-34 tahun sebesar 15\%, responden yang berusia 35-39 tahun sebesar 14\%, responden yang berusia 40-44 tahun sebesar 12\%, responden yang berusia 45-49 tahun sebesar 10\%, responden yang berusia 50-54 tahun sebesar 9\% dan persentase paling rendah adalah responden yang berusia 5559 tahun sebesar $6 \%$. 


\section{b. Responden Berdasarkan Jenis Kelamin}

Reponden yang terbesar adalah berjenis kelamin laki-laki dengan persentase $91 \%$ dan yang terendah berjenis kelamin perempuan sebesar $9 \%$.

Responden Berdasarkan Jenis Kelamin

\section{c. Responden Berdasarkan Pendidikan Terakhir}

Responden yang terbesar adalah yang memiliki pendidikan akhir SMA sebesar 68\%, selanjutnya responden dengan pendidikan akhir S-1 sebesar 19\%, kemudian responden dengan pendidikan akhir Diploma sebesar 7\%, dan yang terendah persentasenya adalah responden pendidikan akhir S-2 dan SMP sebesar $1 \%$.

\section{d. Responden Berdasarkan Pekerjaan}

Responden dengan persentase terbesar adalah supir yaitu $40 \%$, kemudian staf pegawai biasa sebesar $23 \%$, selanjutnya pedagang sebesar $19 \%$, pekerjaan sebagai PNS sebesar $8 \%$, pelajar sebesar $4 \%$, pensiunan, manajer dan supervisor masing-masing sebesar $2 \%$, dan yang presentase paling rendah adalah direktur dan notaris sebesar $1 \%$.

\section{e. Responden Berdasarkan Jumlah Anggota Keluarga Yang Ditanggung}

Responden dengan persentase jumlah anggota keluarga terbesar adalah berjumlah dua yaitu $36 \%$, kemudian yang berjumlah satu sebesar $25 \%$, selanjutnya yang berjumlah tiga sebesar $16 \%$, yang berjumlah empat sebesar $11 \%$, yang berjumlah lainnya sebesar $7 \%$, dan presentase yang paling rendah untuk jumlah anggota keluarga yang ditanggung adalah yang berjumlah lima sebesar $5 \%$.

\section{f. Responden Berdasarkan Maksud Perjalanan}

Responden dengan persentase tertinggi adalah responden yang tujuan perjalanannya untuk bekerja/bisnis sebesar $52 \%$, selanjutnya responden yang tujuan perjalanannya untuk jalan-jalan sebesar 18\%, berkunjung sebesar $17 \%$, liburan sebesar $7 \%$, belanja sebesar $5 \%$, dan yang paling terendah responden yang tujuan perjalanannya untuk lainnya yaitu sebesar $1 \%$.

\section{g. Responden Berdasarkan Penghasilan Per Bulan}

Responden dengan persentase paling tinggi memiliki pendapatan adalah $>5$ juta/bulan sebesar $39 \%$, kemudian responden dengan pendapatan 2-3 juta/bulan sebanyak $29 \%$, selanjutnya responden yang memiliki pendapatan 3-4 juta/bulan sebesar $17 \%$, responden dengan pendapatan 1-2 juta/bulan sebesar 7\%, pendapatan sebesar 4-5 juta/bulan sebesar $6 \%$, dan yang menjadi responden persentase terkecil dengan pendapatan sebesar 500 ribu-1 juta sebesar $2 \%$.

\section{h. Responden Berdasarkan Pengeluaran Biaya} Transportasi Per Bulan

Responden dengan persentase paling tinggi memiliki pengeluaran biaya transportasi 1 juta ke atas/bulan sebesar $49 \%$, kemudian responden dengan pengeluaran biaya transportasi 600-800 ribu/bulan sebesar 32\%, selanjutnya responden yang memiliki pengeluaran biaya transportasi 800 ribu-1 juta/bulan sebesar $15 \%$, responden dengan pengeluaran biaya transportasi 400-600 ribu/bulan sebesar $3 \%$, dan yang menjadi responden persentase terkecil dengan pengeluaran biaya transportasi 200-400 ribu/bulan sebesar $1 \%$.

\section{i. Responden Berdasarkan Frekuensi Perjalanan}

Responden dengan persentase yang paling tinggi untuk frekuensi perjalanan adalah 1-2 kali 40\%, kemudian responden dengan frekuensi perjalanan 3-4 kali sebesar $37 \%$, dan yang menjadi responden persentase terkecil dengan frekuesi perjalanan $>3$ kali adalah sebesar $23 \%$.

\subsection{Analisis Tarif Berdasarkan ATP}

Berdasarkan karakteristik responden yang telah dijelaskan sebelumnya, maka dapat dilakukan analisis tarif berdasarkan ATP dengan menggunakan metode household budget. Hasil share pengeluaran biaya transportasi dan share pengeluaran biaya jalan tol didapatkan dari jawaban setiap responden dalam menjawab pertanyaan kuesioner. Untuk menentukan nilai ATP menggunakan persamaan 2.1, dimana persamaan tersebut menggunakan nilai rata-rata pendapatan per bulan, persen biaya transportasi perbulan, persen biaya tol perbulan dan nilai frekuensi perjalanan. Untuk perhitungan ATP.

Diketahui bahwa ATP tarif dasar jalan tol Sigli - Banda Aceh berdasarkan besarnya rata-rata ATP kendaraan golongan I (LV) yaitu Rp 60.193,-/trip untuk kendaraan golonngan IIA (MHV) yaitu Rp 174.089,-/trip dan untuk kendaraan golongan IIB (LT \& LB) yaitu Rp 120.579,-/trip.

\subsection{Analisis Tarif Berdasarkan WTP}

Berdasarkan karakteristik responden yang telah dijelaskan sebelumnya, maka dapat diketahui tarif berdasarkan WTP atau kemauan seseorang dalam membayar tarif tol Sigli Banda Aceh. Analisis WTP.

Diketahui bahwa WTP tarif dasar Jalan Tol Sigli Banda Aceh tiap kelompok, untuk kendaraan golongan I (LV) yaitu Rp 52.305,- yang dibulatkan menjadi Rp 53.000,- untuk kendaraan golongan IIA (MHV) yaitu Rp 116.042,- yang dibulatkan menjadi Rp 116.000,- dan untuk golongan IIB (LT \& LB) yaitu Rp 129.066,- yang dibulatkan menjadi Rp 116.000,-. 
Pada pembahasan ini disajikan dari hasil pengolahan data dan analisis data, yaitu Analisis Rencana Tarif Jalan Tol Berdasarkan Pendekatan Willingness To Pay (WTP) dan Ability To Pay (ATP) Pada Rencana Ruas Jalan Tol Sigli Banda Aceh.

Berdasarkan tarif ATP tol Sigli - Banda Aceh untuk kendaraan golongan I (LV) yaitu Rp 60.193,-/trip yang dibulatkan menjadi Rp 60.000,-/trip, untuk kendaraan golongan IIA (MHV) yaitu Rp 174.089,-/trip yang dibulatkan menjadi Rp 174.000,-/trip dan untuk kendaraan golongan IIB (LT \& LB) yaitu Rp 120.579,-/trip yang dibulatkan menjadi Rp 121.000,-/trip tarif tersebut didapat dari nilai rata-rata ATP dari setiap golongan kendaraan.

Tarif berdasarkan WTP Jalan Tol Sigli - Banda Aceh untuk kendaraan golongan I (LV) yaitu Rp 52.305,- yang dibulatkan menjadi Rp 53.000,- untuk kendaraan golongan IIA (MHV) yaitu Rp 129.066,- yang dibulatkan menjadi Rp 130.000,- dan untuk kendaraan golongan IIB (LT \& LB) yaitu Rp 116.042,- yang dibulatkan menjadi Rp 116.000,-Nilai dari perhitungan berdasarkan WTP lebih rendah dari pada nilai ATP nya, kondisi ini menunjukkan bahwa kemampuan membayar lebih besar dari pada keinginan atau kemauan dalam membayar jasa tersebut. Pada kondisi ini terjadi apabila pengguna memiliki penghasilan yang relatif tinggi tetapi antusias terhadap jasa tersebut relatif rendah.

Dapat disimpulkan bahwa tarif yang direkomendasikan pada penelitian ini untuk kendaraan golongan I (LV) sebesar Rp 56.000,-, untuk kendaraan golongan IIA (MHV) sebesar Rp 152.000,-, untuk kendaraan golongan IIB (LT \& LB) sebesar Rp 118.500,-.

Pada penelitian ini didapatkan hasil dari nilai pendapatan kendaraan komersial dimana hasil tersebut menjadi kelemanan pada penelıtian 1nı, yang mana penelitıan $1 \mathrm{n} 1$ seharusnya menggunakan nilai pendapatan keluarga dengan menggunakan metode Household Budget, maka diperlukan penelitian berkala untuk kesempurnaan hasil penelitian selanjutnya.

\section{Kesimpulan}

1. Jumlah responden pada penelitian ini diketahui bahwa reponden yang lebih banyak adalah berjenis kelamin laki-laki dengan persentase $91 \%$.

2. Tujuan responden dengan persentase tertinggi adalah responden yang tujuan perjalanannya untuk bekerja/bisnis sebesar $52 \%$.

3. Dari hasil analisis tarif berdasarkan ATP dan WTP, maka dapat diketahui tarif dasar Jalan Tol Sigli Banda Aceh berdasarkan ATP yang untuk kendaraan golongan I sebesar Rp 60.193,-/trip golongan IIA sebesar Rp 174.089,-/trip dan golongan IIB sebesar Rp 120.579,-/trip lebih besar jika dibandingkan dengan WTP, dimana untuk golongan I sebesar Rp 52.305,- golongan IIA sebesar Rp 129.066,- dan golongan IIB Rp 116.042,--

4. Dapat disimpulkan bahwa tarif yang direkomendasikan pada penelitian ini untuk kendaraan golongan I (LV) sebesar Rp 56.000,-, untuk kendaraan golongan IIA (MHV) sebesar Rp 152.000,-, untuk kendaraan golongan IIB (LT \& LB) sebesar Rp 118.500,-.

\section{Saran}

Adapun saran yang dapat diberikan dari hasil penelitian ini adalah :

1. Adanya Diharapkan dapat menjadi bahan informasi bagi mahasiswa teknik sipil pada khususnya dan masyarakat pada umumnya, mengenai kemampuan atau daya bayar masyarakat Aceh terhadap jalan tol Sigli - Banda Aceh nanti.

2. Diharapkan adanya penelitian selanjutnya untuk meninjau lebih mendalam mengenai rencana tarif jalan tol berdasarkan ATP dan WTP. Dalam penelitian ini hasil yang didapatkan dari nilai pendapatan kendaraan komersial dimana hasil tersebut menjadi kelemahan pada penelitian ini. Penelitian selanjutnya disarankan menggunakan nilai pendapatan keluarga dengan menggunakan metode Household Budget, sehingga diperlukan penelitian berkala untuk kesempurnaan hasil penelitian selanjutnya.

\section{Daftar Pustaka}

[1] Adanı, Analısis Atp/Wtp rada Kencana Jalan Iol Kraksaan - Bayuwangi, Universitas Brawijawa, Malang, 2017.

[2] Anggraini, R, Kajian Penentuan Tarif Bus Trans Koetaradja Berdasarkan Ability To Pay (ATP) dan Willingness To Pay (WTP). Universitas Syiah Kuala, Banda Aceh, 2019.

[3] Ariamsah, S.D, Analisa Tarif Jalan Tol Berdasarkan Pendekatan WillingnessTo Pay (WTP) dan Ability To Pay (ATP). Studi Kasus : Jalan Tol Waru - Juanda, Universitas Muhammadiyah Malang, Malang, 2015.

[4] Fadhurrozi, A, Analisis Travel Cost Budget (TCB) dan Ability To Pay (ATP) Pengguna Trans Koetaradia Berdasarkan Pendapatan Rumah Tangga Di Banda Aceh. Universitas Syiah Kuala, Banda Aceh, 2019.

[5] Hensher, D.A. Stated Preference Analysis of Travel Choices: The State of Practice, Transportasi 21, 1994.

[6] Hanifah, Analisis Tarif Bus Trans Koetaradja Berdasarkan Biaya Operasional Kendaraan, Ability To Pay dan Willingness To Pay (Studi Kasus Koridor I Keudah - Darussalam), Universitas Syiah Kuala, Banda Aceh, 2017.

[7] Hair. J.F, Multivariate Data Analysis, Edisi 5, Gramedia Pustaka Utama, Jakarta, 2006.

[8] Julien, Analisis Ability To Pay Dan Willingness To Pay Pengguna Jasa Kereta Api Bandara Kuala Namu, Universitas Sumatera Utara, Medan, 2014.

[9] Keputusan Menteri Pekerjaan Umum Nomor 370KPTS-M-2007, Penetapan Golongan Jenis Kendaraan Pada Ruas Jalan Tol Yang Sudah Beroperasi Dan Besarnya Tarif Tol Pada Beberapa Ruas Jalan Tol, 2007.

[10] Muhammad, N, Pendekatan Traif Jalan Tol Berdasarkan Pendekatan ATP dan WTP (Studi Kasus : Rencana Jalan Tol Solo - Karanganyar), Universitas Brawijaya, Malang, 2017.

[11] Panjaitan, I, Analisa Tarif Tol Berdasarkan Pendekatan Willingness To Pay (WTP) dan Ability To 
Pay (ATP) Studi Kasus Rencana Jalan Tol Medan Binjai, Universitas Sumatera Utara, Medan, 2013.

[12] Qasim, Studi Penentuan Tarif Tol Rencana Ruas Jalan Tol Banda - Aceh Sigli Berdasarkan pendekatan WTP dan ATP, Universitas Syiah Kuala, Banda Aceh, 2019.

[13] Republik Indonesia, Undang-Undang No 38 Tahun 2004 tentang Jalan, Kementrian Hukum dan Hak Asasi Manusia, Jakarta, 2004.

[14] Saiful, Evaluasi Tarif dan Pelayanan Angkutan Kota Trayek Sidoarjo - Krian Berdasarkan Biaya Operasional Kendaraan, Universitas Muhammadiyah, Malang, 2006.

[15] Sugiyono, Metode Penelitian Bisnis. Edisi 1, Alfabeta, Bandung, 2003.

[16] Soehartono, I. Metode Penelitian Sosial. Penerbit: PT. Remaja Rosdakarya, Bandung, 2004.

[17] Tamin, O.Z, Perencanaan dan Permodelan Transportasi, Penerbit ITB, Bandung, 2008.

[18] Warpani, Pengelolaan Lalu Lintas dan Angkutan Jalan, Penerbit ITB, Bandung, 2002.

[19] Yogo, Pembebanan Jaringan Jalan Dari Pintu Keluar Pelabuhan Bakauheni Dengan Adanya Jalan Tol Trans Sumatera, Universitas Lampung, 2018. 